\title{
Global variances in infection control practices for vancomycin resistant Enterococcus - results of an electronic survey
}

\author{
H. Isenman ${ }^{1}$, J. Michaels ${ }^{1}$ and D. Fisher ${ }^{1,2^{*}}$
}

\begin{abstract}
An electronic survey was disseminated amongst infection control practitioners to investigate the variation in practices toward vancomycin resistant enterococci. There were 235 analysable responses, mostly from doctors, in 48 countries. The survey considered active surveillance, in-hospital precautions and tagging and untagging processes. There was a great variation in responses between and within countries highlighting a gap in guidance for practitioners on which to base institutional policy.
\end{abstract}

Keywords: VRE, Infection control, International guidelines

\section{Introduction}

Vancomycin resistant Enterococcus (VRE) emerged internationally through the 1990's. Prevalences today vary widely, with between 0 and $45 \%$ of $E$. faecium isolates demonstrating glycopeptide resistance in European countries [1]. In the United States of America (US) $3 \%$ of hospital acquired infections were due to VRE [2]. The risk of invasive disease in VRE colonized patients is $4 \%$ but can be upto $14 \%$, in immune suppressed patients, highlighting the importance of infection control measures especially in countries with a high prevalence $[3,4]$.

In the last 10 years, however, uncertainty has increased regarding the infection control prioritisation of this organism. Initially there were concerns over horizontal gene transfer and the possible emergence of Vancomycin Resistant $S$. aureus but this situation has not been realized. The treatment paradigm for VRE improved with the advent of linezolid and daptomycin in 2000 and 2003.

Now, in the era of carbapenemase producers and polymixin resistance, many question where as a priority VRE control should sit. The optimal approach to screening,

\footnotetext{
* Correspondence: mdcfda@nus.edu.sg

1 Division of Infectious Diseases, National University Hospital, Singapore, Singapore

${ }^{2}$ Yong Loo Lin School of Medicine, National University of Singapore,

Singapore, Singapore
}

(c) The Author(s). 2016 Open Access This article is distributed under the terms of the Creative Commons Attribution 4.0 International License (http:/creativecommons.org/licenses/by/4.0/, which permits unrestricted use, distribution, and reproduction in any medium, provided you give appropriate credit to the original author(s) and the source, provide a link to the Creative Commons license, and indicate if changes were made. The Creative Commons Public Domain Dedication waiver (http://creativecommons.org/publicdomain/zero/1.0/) applies to the data made available in this article, unless otherwise stated.

\section{Methods}

An electronic survey was created on survey monkey [7]. The survey was kept concise to facilitate contributions and required just a few minutes. The full survey is attached in the Additional file 1.

\section{Recruitment of participants}

The link was forwarded to members of the International Society of Chemotherapy (ISC) infection control workgroup, the Infection Prevention Society (UK) and $\mathrm{Oz}$ bug (Australian list server). Personal contacts of the authors outside of these organisations were also invited to participate, and all recipients were asked to further refer the link to infection control practitioner colleagues world-wide. 
Questions were multiple choice, most had a free text option and none were compulsory (Fig. 1). Optional demographic information included name, occupation, email address, type and country of institution. Areas assessed included VRE active surveillance, infection control precautions undertaken and labelling of patients. These terms were not specifically defined. Responses where the institution or country was not named were eliminated. Where more than one response was received from the same institution, the majority/most consistent response was selected and responses were merged.

The initial analysis reviewed all institutional responses, then a more focused analysis of countries with four or more institutions represented was performed to assess for international and intranational variation.

\section{Results}

\section{Demographics}

There was a total of 235 responses from 48 countries, with 189 institutions represented (see Table 1 for the full country list). Of the 234 who provided occupation details, 161 (69\%) were doctors, 51 (22\%) nurses, and 22 (9\%) other including medical laboratory scientists, pharmacists, infection control staff, clinical scientists microbiologists and an epidemiologist.
Of the 234 respondents who provided information regarding their place of work, the majority were in acute care, with 177 (76\%) from a tertiary referral centre, and 48 (20 \%) from an acute care hospital. Only nine (4\%) were from a non-acute health care facility or hospital.

\section{Priority of VRE}

VRE was given a high infection control priority with specific efforts in 95 (51\%) of the 187 institutions that responded to the question. It was prioritized "similar to other infection prevention efforts" by 51 (27\%), low priority 28 (15\%) and rarely considered in only 13 (7\%).

\section{Screening}

Of 187 institutional responses to screening, active surveillance was practiced by 135 (72 \%) with 18 (9\%) of those stating it was universal, and the remaining targeted. A minority, 39 (21 \%) performed no surveillance at all, and $13(7 \%)$ performed surveillance on stool cultures sent for other reasons.

Of the 117 institutions that employ targeted screening, 42 (36 \%) didn't respond to the question regarding which target group they select. 52 (44 \%) screen those that are at high risk for disease such as the immune suppressed, and $23(20 \%)$ targeted patients at high risk for a positive result such as previous antibiotic exposure or

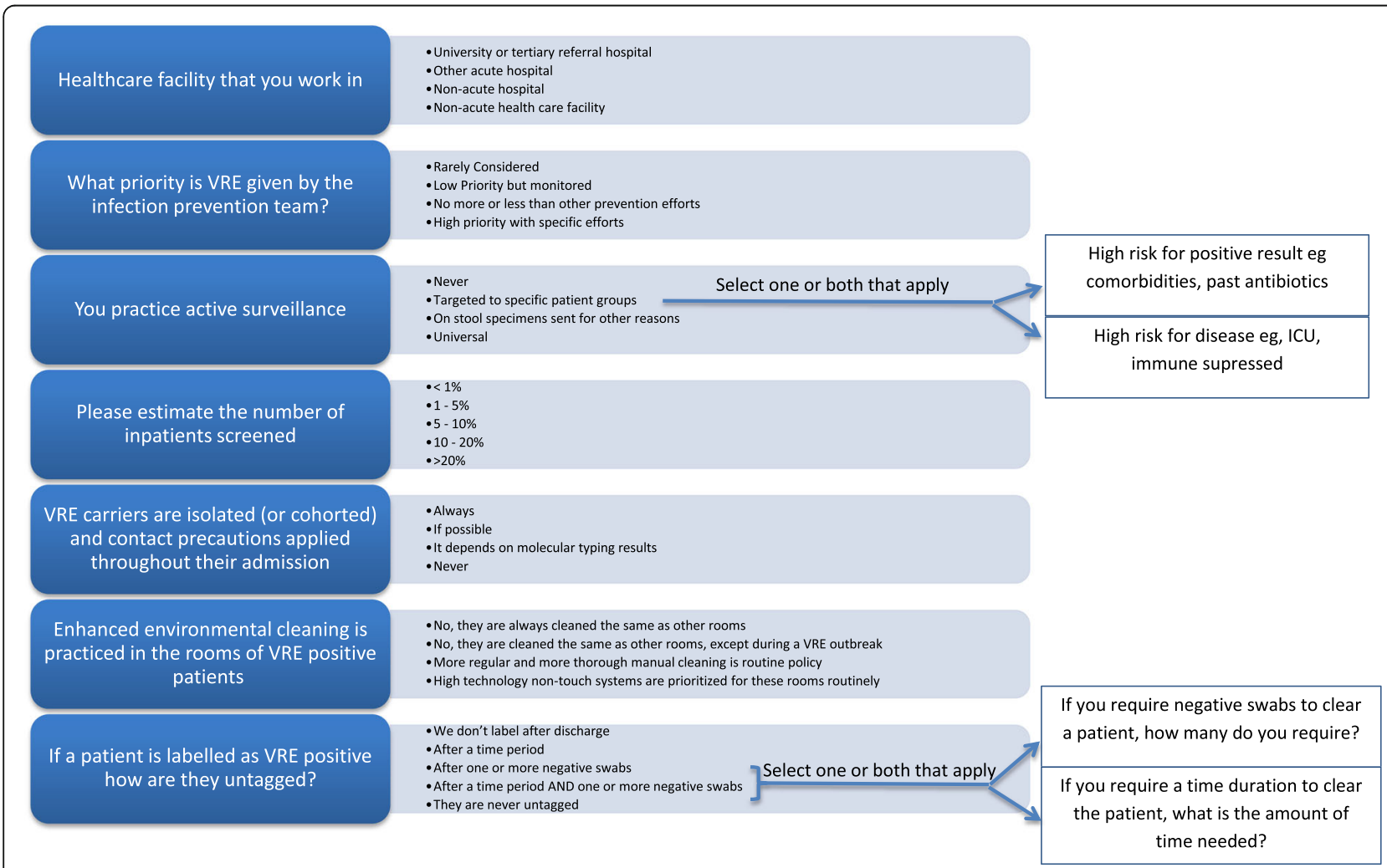

Fig. 1 Non Demographic VRE Survey Questions (arrows show the follow on questions for respondents who selected the answer leading to the arrow) 
Table 1 Countries with four or more institutions represented: (Number, with percentage relating to the total responses from that country per specific question)

\begin{tabular}{|c|c|c|c|c|c|c|c|c|c|c|c|c|c|}
\hline \multirow[b]{2}{*}{$\begin{array}{l}\text { Country } \\
\text { (No Institutions Responded) }\end{array}$} & \multicolumn{4}{|l|}{ Screening } & \multicolumn{4}{|l|}{ Cleaning } & \multicolumn{5}{|l|}{ Untagging } \\
\hline & Universal & Never & Targeted & On stool & $\begin{array}{l}\text { Same as } \\
\text { others }\end{array}$ & $\begin{array}{l}\text { Increase in } \\
\text { outbreak }\end{array}$ & $\begin{array}{l}\text { High tech } \\
\text { non touch }\end{array}$ & $\begin{array}{l}\text { More than } \\
\text { others }\end{array}$ & Don't label & After time & After swab & $\begin{array}{l}\text { After time + } \\
\text { swab }\end{array}$ & $\begin{array}{l}\text { Never } \\
\text { Untag }\end{array}$ \\
\hline Australia (37) & $3(8)$ & $3(8)$ & $31(84)$ & - & $2(6)$ & $6(18)$ & $1(3)$ & $25(73)$ & $2(6)$ & $3(9)$ & $3(9)$ & $16(45)$ & $11(31)$ \\
\hline Canada (4) & $3(75)$ & - & $1(25)$ & - & - & - & - & $4(100)$ & - & - & $1(25)$ & $2(50)$ & $1(25)$ \\
\hline China (4) & - & $1(25)$ & $1(25)$ & $2(50)$ & $1(25)$ & - & - & $3(75)$ & - & $1(25)$ & $2(50)$ & $1(25)$ & - \\
\hline Denmark (8) & $4(57)$ & $1(14)$ & $2(28)$ & - & - & $1(14)$ & $3(43)$ & $3(43)$ & - & $2(29)$ & $3(43)$ & $1(14)$ & $1(14)$ \\
\hline Malaysia (6) & $1(17)$ & $4(66)$ & - & $1(17)$ & - & $2(33)$ & - & $4(67)$ & $2(33)$ & - & $1(17)$ & - & $3(50)$ \\
\hline Netherlands (5) & & $1(20)$ & $4(80)$ & - & $1(25)$ & - & - & $4(80)$ & - & - & - & $5(100)$ & - \\
\hline New Zealand (7) & - & $1(14)$ & $5(72)$ & $1(14)$ & - & $1(17)$ & $1(17)$ & $4(66)$ & - & - & - & $2(33)$ & $4(67)$ \\
\hline Singapore (7) & - & - & $7(100)$ & - & - & $2(40)$ & - & $3(60)$ & - & $1(14)$ & - & $6(86)$ & - \\
\hline Turkey (5) & - & - & $5(100)$ & - & - & - & - & $5(100)$ & $1(20)$ & - & - & $2(40)$ & $2(40)$ \\
\hline UK (31) & $5(17)$ & $10(33)$ & $12(40)$ & $3(10)$ & $4(14)$ & $4(14)$ & $4(14)$ & $16(57)$ & $5(18)$ & $1(3)$ & $3(11)$ & $2(7)$ & $17(21)$ \\
\hline USA (22) & - & $8(36)$ & $11(50)$ & $3(14)$ & $11(50)$ & $4(20)$ & $4(20)$ & $2(10)$ & $2(9)$ & $3(14)$ & $7(32)$ & $6(27)$ & $4(18)$ \\
\hline
\end{tabular}

Countries with fewer than four institutional responses: Namibia, Argentina, Brazil, Belarus, Belgium, Bulgaria, Chile, DRC, Egypt, France, Germany, Greece, Hungary, Iceland, India, Japan, Malta, Nepal, Nigeria, Norway, Pakistan, Portugal, Qatar, Republic of Korea, Romania, Russia, Slovakia, Slovenia, South Africa, Spain, Sri Lanka, Sweden, Switzerland, Taiwan, Thailand 
multiple comorbidities. Fourteen (12\%) selected both groups for screening.

Of 113 institutions quantifying the admissions screened for VRE, 94 ( $83 \%$ ) would screen up to $10 \%$; (25 (22 \%) less than $1 \%, 42$ (37 \%) 1-5 \%, 5-10\%, 27 $(24 \%))$. Only 19 (17\%) screened more inpatients, with 8 (7\%) screening $10-20 \%$, and 11 (10\%) screening over $20 \%$ of inpatients.

\section{Type of contact precautions}

Of the 178 who completed the question, 116 (65\%) always isolate identified colonized patients, 47 (26\%) isolate if possible, and $10(5 \%)$ never isolate: Namibia (1), Egypt (1), Sri Lanka(1), Argentina (1), DRC (1), Nigeria (1), USA (4). Only five (3\%) institutions use molecular typing results to guide isolation strategies: Australia (1), Canada (1), China (1), UK (3).

\section{Environmental cleaning}

Of 171 who responded, 93 (54\%) perform more regular and more thorough manual cleaning. Fifty eight (34\%) would clean the same as other rooms, of which 28 (16\%) would use increased cleaning efforts during an outbreak. High technology non touch systems were employed by 20 (12\%) in UK (4), USA (4), Denmark (3), Belgium, (2), Malta, Nepal, Belarus, New Zealand, Romania, Qatar and Australia (1 each).

\section{'Untagging' of colonized patients}

Of 173 responding institutions, 54 (31\%) would not untag patients. Of the 96 (56\%) who do untag patients, $12(7 \%)$ would untag patients after a time period alone, 28 (16\%) would untag after a negative swab(s) alone, and 56 (33\%) require both a time period and one or more negative swabs to untag. Twenty three $(13 \%)$ do not label patients after discharge.

Of the 82 institutions that described their swab requirement for untagging patients, the majority of institutions require $2,(28 \%)$ or 3 , (54 \%) swabs to be negative, whilst $10 \%$ required one swab only. Seven respondents $(8 \%)$ required 4 or more swabs before untagging a patient as a VRE carrier.

The time period to clear patients likewise demonstrated great variation. Of the 68 institutions that nominated a time period as a criterion just 58 quantified it with $47(81 \%)$ clearing patients within a year: $15(26 \%)$ 12 months, 17 (29 \%) 6 months, and 15 (26\%) 3 months. Only $10(17 \%)$ required 24 months to clear a patient, and 1 (1\%) over 24 months.

\section{Intranational variation}

Eleven countries (Australia, Canada, China, Denmark, Malaysia, Netherlands, New Zealand, Singapore, Turkey, UK, US) had responses from four or more institutions.
VRE was highly prioritized or prioritized the same as other MDROs by the majority of countries, however in the US there was almost equal spread between affording VRE a high priority (36\%), the same as other MDROs $(27 \%)$ and a low priority (36\%). The UK also varies in its approach with $43 \%$ giving VRE high priority, $27 \%$ the same as other MDROs and $23 \%$ a low priority, with $7 \%$ rarely considering it. Table 1 outlines the approaches to screening, cleaning and untagging.

There was less heterogeneity in the approach to contact precautions, with most countries always using contact precautions in over $50 \%$ of institutions (with the exception of Turkey at $40 \%$ ), and the remainder of institutions employing contact precautions where possible. The USA showed a varied approach between institutions with universal use in $82 \%$ and never using contact precautions in $18 \%$. In only Canada, Singapore and Turkey did all institutions responding undertake active surveillance. All other countries had respondents divided on the issue of active surveillance or not. Full data on contact precautions, VRE prioritization and number of inpatients screened can be found in the Additional file 2: Table S1.

\section{Discussion}

This international survey has highlighted the variation in infection control approaches to VRE, within and between countries. Internationally, VRE still registers as an agent of concern with $81 \%$ prioritizing it equal to or above other infection control efforts. Surveillance is undertaken in $72 \%$ of responding institutions, with the majority rationalizing and finding merit in targeting high risk groups mostly by risk of severe disease, but many by risk of a positive result.

Although we received responses from 48 countries; we were reluctant to equate small numbers of responses from one country as truly representative; indeed the widest variation in approach was seen in countries with the greatest number of institutional responses such as the UK and US.

Practices also don't necessarily reflect local epidemiology as VRE prevalence in the UK is $21 \%$ [1], however it is seen as high priority in only $43 \%$ of responding institutions and accordingly a third of institutions undertaken no active screening. Countries with a lower prevalence of VRE such as Denmark (4.5\%) and the Netherlands (1.1\%), prioritise VRE more highly (80 and $75 \%$ ), and more consistently isolate patients (71 and $100 \%$ ), alongside tagging at discharge [1].

The different approaches to infection prevention processes across institutions in the UK and USA, may in part be due to the fact that the infection control guidelines for these countries were last updated in 2006 [5, 6]. For instance active surveillance in the UK guideline is 
reserved for outbreaks while in the US there are several choices including point prevalence surveillance periodically, testing of "at risk" patients and testing roommates of VRE positive patients. Such advice now is not adhered to nor is it relevant in the setting of endemic VRE.

Responses from countries with more recently updated guidelines such as Singapore [8] showed greater yet still imperfect consistency.

The variance in approaches within any country may also be explained by differing views on the efficacy of contact precautions to prevent transmission. A study of discontinuation of contact precautions of haematology patient's admitted to single rooms in a unit in a before/ after study showed no significant difference in VRE blood stream infection (BSI) between time periods [9]. Another Canadian study comparing rates of VRE BSI between hospitals that employ screening and isolation and those that abandoned screening, found a rise in VRE BSI in all hospitals, but the rate of increase was highest in non-screening hospitals - this study is not yet complete however [10].

In terms of environmental cleaning, it was notable that $11 \%$ use high technology non touch cleaning systems. The benefit of this technology has been shown to significantly reduce VRE acquisition in new occupants of rooms previously occupied by VRE positive patients [11].

Emerging as a "casual" survey, the response was beyond the authors' expectations. We believe this was because the questions in hand were of genuine interest to respondents in these 48 countries. Furthermore, the study was designed to attract responses in being brief, and permitting a response from anyone with self perceived adequate local knowledge. No question was compulsory so survey respondents could progress if they could not or preferred no to answer, although still each question saw $>100$ responses. These strengths were also to some extent a weakness. Our study has many inherent shortcomings. There was no selection of institutions or participants and no submissions have been validated. Additionally, as we did not provide definitions for terms used such as untagging, it is possible that some questions were misinterpreted as it is hard to believe that universal active surveillance (intended to mean rectal swabbing and culture of patients on admission) is undertaken to this extent. The method of recruitment of participants provides selection bias towards more active infection control teams, and therefore more aggressive approaches may be overrepresented in the survey.

Despite the shortcomings of our methods, we found considerable variation in reported practices. Untagging of patients is either never done, or automatic on discharge or in between where the time course can be months to years and negative swabs required can be from 0 to 6 . Given the lack of data in this area to inform practice, this variation is unsurprising. Practitioners in hospitals therefore are forced to create institutional policy. These policies and therefore practices will be based on personal viewpoints, local epidemiology (national as well as affecting that healthcare facility), the available infrastructure and capacity to isolate as well as competition for infection control resources from newer emerging multi drug resistant organisms (MDROs).

Our survey highlights reported variation in infection control practices related to VRE. Further research on optimal infection prevention practices and development of guidance in this area is warranted. The survey represents a request from infection control practitioners in 48 countries for the development of a guideline that can be adapted to a nation's or a hospital's requirements. Until that time practices will remain chaotic with the ensuing suboptimal use of infection control resources internationally.

\section{Additional files}

Additional file 1: The full survey questionairre. (PDF $95 \mathrm{~kb}$ )

Additional file 2: Table S1. Countries with four or more institutions represented: (Number, with percentage relating to the total responses from that country per specific question). (DOCX $14 \mathrm{~kb}$ )

\section{Abbreviations}

BSI: Blood stream infection; CDC: Centres for disease control and prevention; ISC: International Society for Chemotherapy; MDROs: Multi drug resistant organisms; UK: United Kingdom; US: United States (of America);

VRE: Vancomycin resistant Enterococci

\section{Acknowledgement}

The authors would like to acknowledge the participants of the survey from over 48 countries together with the individuals and societies that facilitated dissemination.

Funding

This study required no funding support.

Availability of data and materials

Not applicable.

\section{Authors' contribution}

$\mathrm{HI}$ and DF designed the study. JM created the electronic version and ensured formatting to produce the raw data. $\mathrm{HI}$ analysed the data and drafted the manuscript. DF undertook most of the survey recruitment edited and created the final version. All authors read and approved the final manuscript.

\section{Competing interest}

The authors declare that they have no competing interests.

Consent for publication

Our manuscript does not contain any individual personal data, so consent is not applicable.

Ethics approval and consent to participate

Ethics approval was not applicable; exemption provided by the National healthcare group Domain Specific Research Board (NHG DSRB) 2016/00681. 
Received: 6 July 2016 Accepted: 10 October 2016

Published online: 03 November 2016

\section{References}

1. Antimicrobial Resistance Surveillance in Europe. 2014. European Antimicrobial Resistance Surveillance Network (EARS-Net) http://ecdc. europa.eu/en/publications/Publications/antimicrobial-resistance-europe2014.pdf. Accessed 25 June 2016.

2. Sievert DM, Ricks P, Edwards JR, et al. Antimicrobial-resistant pathogens associated with healthcare-associated infections: summary of data reported to the National Healthcare Safety Network at the Centers for Disease Control and Prevention, 2009-2010. Infect Control Hosp Epidemiol. 2013;34:1-14.

3. Olivier CN, Blake RK, Steed LL, Salgado CD. Risk of vancomycin-resistant Enterococcus (VRE) bloodstream infection among patients colonized with VRE. Infect Control Hosp Epidemiol. 2008:29(5):404-9.

4. Zaas AK, Song X, Tucker P, Perl TM. Risk factors for development of vancomycin-resistant enterococcal bloodstream infection in patients with cancer who are colonized with vancomycin-resistant enterococci. Clin Infect Dis. 2002;35:1139-46.

5. Cookson BD, Macrae MB, Barrett SP, et al. Guidelines for the control of glycopeptide-resistant enterococci in hospitals. J Hosp Infect. 2006;62(1):6-21.

6. Siegel JD, Rhinehart E, Jackson M, Chiarello L, Healthcare Infection Control Practices Advisory Committee. Management of multidrug-resistant organisms in health care settings, 2006. Am J Infect Control. 2007;35(10 Suppl 2):S165-93.

7. SurveyMonkey Inc. Palo Alto, California, USA. 2016. Website https://www. surveymonkey.com. Accessed 13 Oct 2016.

8. Guidelines For Control And Prevention Of Multi-Drug Resistant Organisms (MDROs) In Healthcare Facilities Ministry of Health Singapore (2013) https:/www.moh.gov.sg/content/dam/moh_web/Publications/Guidelines/ Infection\%20Control\%20guidelines/GUIDELINES\%20FOR\%20CONTROL\% 20AND\%20PREVENTION\%20OF\%20MULTI-DRUG\%20RESISTANT\% 20ORGANISMS\%20\%28MDROS\%29\%20IN\%20HEALTHCARE\%20FACILITIES\%20\%20Nov\%202013.pdf. Accessed 25 June 2016

9. Almyroudis NG, Osawa R, Samonis G, et al. Discontinuation of Systematic Surveillance and Contact Precautions for Vancomycin-Resistant Enterococcus (VRE) and Its Impact on the Incidence of VRE faecium Bacteremia in Patients with Hematologic Malignancies. Infect Control Hosp Epidemiol. 2016:37(4):398-403.

10. Lam F, Johnstone J, Adomako K, et al. Vancomycin Resistant Enterococcus (VRE) Rates in Ontario, Canada After the Discontinuation of VRE Screening and Control Practices by Some Hospitals: Interim Results. Open Forum Infect Dis. 2014;1 suppl 1:S257.

11. Dancer S. Controlling Hospital-Acquired Infection: Focus on the Role of the Environment and New Technologies for Decontamination. Clin Microbio Rev. 2014;27(4):665-90.

\section{Submit your next manuscript to BioMed Central and we will help you at every step:}

- We accept pre-submission inquiries

- Our selector tool helps you to find the most relevant journal

- We provide round the clock customer support

- Convenient online submission

- Thorough peer review

- Inclusion in PubMed and all major indexing services

- Maximum visibility for your research

Submit your manuscript at www biomedcentral.com/submit 